\title{
Outcomes in octogenarians undergoing coronary artery bypass grafting
}

\author{
Roger Baskett, Karen Buth, William Ghali, Colleen Norris, Tony Maas, Andrew Maitland, \\ David Ross, Rand Forgie, Gregory Hirsch
}

\section{Abstract}

Background: Although octogenarians are being referred for coronary artery bypass grafting (CABG) with increasing frequency, contemporary outcomes have not been well described. We examined data from 4 Canadian centres to determine outcomes of CABG in this age group.

Methods: Data for the years 1996 to 2001 were examined in a comparison of octogenarians with patients less than 80 years of age. Logistic regression analysis was used to adjust for preoperative factors and to generate adjusted rates of mortality and postoperative stroke.

Results: A total of 15070 consecutive patients underwent isolated CABG during the study period. Overall, 725 (4.8\%) were 80 years of age or older, the proportion increasing from $3.8 \%$ in 1996 to $6.2 \%$ in 2001 ( $p$ for linear trend $=0.03$ ). The crude rate of death was higher among the octogenarians $(9.2 \% \mathrm{v}$. $3.8 \% ; p<0.001)$, as was the rate of stroke $(4.7 \%$ v. $1.6 \%, p<$ $0.001)$. The octogenarians had a significantly greater burden of comorbid conditions and more urgent presentation at surgery. After adjustment, the octogenarians remained at greater risk for in-hospital death (odds ratio [OR] 2.64, 95\% confidence interval $[\mathrm{Cl}]$ 1.95-3.57) and stroke (OR 3.25, 95\% Cl $2.15-4.93)$. Mortality declined over time for both age groups ( $p$ for linear trend $<0.001$ for both groups), but the incidence of postoperative stroke did not change ( $p$ for linear trend $=$ 0.61 [age $<80$ years] and 0.08 [age $\geq 80$ years]). Octogenarians who underwent elective surgery had crude and adjusted rates of death (OR 1.31, 95\% Cl 0.60-2.90) and stroke (OR $1.59,95 \% \mathrm{Cl} 0.57-4.44)$ that were higher than but not significantly different from those for non-octogenarians who underwent elective surgery.

Interpretation: In this study, rates of death and stroke were higher among octogenarians, although the adjusted differences in mortality over time were decreasing. The rate of adverse outcomes in association with elective surgery was similar for older and younger patients.

CMAJ 2005;172(9):1183-6

he population is rapidly aging, and an increasing number of octogenarians are being referred for coronary artery bypass grafting (CABG)., ${ }^{1,2}$ Previous single-centre reports from Canada ${ }^{3-5}$ and from abroad $^{1,2,6-8}$ have concluded that elderly patients undergoing cardiac surgery have worse outcomes than younger pa- tients. In addition, these studies have reported higher costs and slower recovery for octogenarians undergoing $\mathrm{CABG}$, a finding that has generated debate over the appropriate use of health care resources. ${ }^{1,5,7,9}$

It has become increasingly clear that the results of CABG among octogenarians, although worse than among younger patients, are better than for percutaneous coronary interventions or medical therapy alone when the extent of the patient's coronary disease is such that revascularization with $\mathrm{CABG}$ is indicated. ${ }^{10,11}$ Similarly, the superior results of percutaneous coronary intervention relative to medical therapy in elderly patients with coronary disease will likely continue to increase the total number of octogenarians undergoing coronary angiography, which in turn will probably increase the number of patients being referred for CABG. ${ }^{10,12}$ Contemporary outcomes for octogenarians undergoing CABG in Canada have not been well described. If we are to have an informed debate and determine appropriate policy, it is important for these outcomes to be known.

We aimed to describe the characteristics and outcomes of patients 80 years of age and older undergoing CABG in Canada and to compare their outcomes with those of younger patients. In addition, we examined changes in results over time.

\section{Methods}

The study group included all consecutive patients undergoing isolated CABG from 1996 to 2001 at 4 Canadian centres (in Edmonton, Calgary, Saint John and Halifax). Patients undergoing CABG associated with heart valve repair or replacement, resection of a ventricular aneurysm or other surgical procedures were excluded. All patient data were collected prospectively according to definitions provided in the Society of Thoracic Surgeons database. ${ }^{13}$ Data for the following variables were collected: age, sex, year of surgery, centre, urgency (elective, urgent [medical condition dictates that the patient must remain in hospital until surgery can be performed] or emergent [the clinical condition requires that surgery be performed without delay]), ejection fraction, diabetes, chronic obstructive pulmonary disease, hypertension, preoperative renal insufficiency, congestive heart failure, history of cerebrovascular disease, peripheral vascular disease, previous myocardial infarction, reoperative surgery and critical left main stenosis. The outcomes of interest were in-hospital death and stroke, the latter defined as a new, permanent neurologic deficit.

Basic $\chi^{2}$ and $t$ tests were used to compare the prevalence of preoperative risk variables in octogenarians and non-octogenari- 
ans, as well as the incidence of death and stroke. Rates of death and stroke were predicted for various patient groups and compared over time by means of analysis of variance. Trends in outcomes over time were compared with the Cochran-MantelHaenszel test ( $p$ trend). Logistic regression techniques were used for multivariate analysis and for the calculation of adjusted rates of the outcomes for octogenarians and younger subjects. ${ }^{14}$ Age was used as a categorical variable, with patients under 70 years of age as the reference group (other categories: $70-74$ years, $75-79$ years, 80 years or older). Ethics approval was obtained from all centres involved in this study.

\section{Results}

From 1996 to 2001, a total of 15070 consecutive patients underwent isolated CABG at the 4 centres; of these, 725 $(4.8 \%)$ were 80 years of age or older. Compared with the younger patients, the octogenarians had a significantly greater burden of comorbidity and more urgent presentation at surgery (Table 1). In particular, a greater proportion of the octogenarians had renal insufficiency, cerebrovascular disease, peripheral vascular disease, critical left main stenosis and heart failure. The only risk factor with greater prevalence in the younger age group was diabetes mellitus (Table 1).

The proportion of patients undergoing CABG who were octogenarians increased over time, from 3.8\% in 1996 to $6.2 \%$ in 2001 ( $p$ for linear trend $=0.03$ ).

The crude rate of death was higher among the octoge-

\begin{tabular}{|c|c|c|c|}
\hline \multicolumn{4}{|c|}{$\begin{array}{l}\text { Table 1: Comparison of patient characteristics for } \\
\text { octogenarians and non-octogenarians }\end{array}$} \\
\hline Variable & $\begin{array}{c}<80 \mathrm{yr} \\
n=14345\end{array}$ & $\begin{array}{l}\geq 80 \mathrm{yr} \\
n=725\end{array}$ & $p$ value \\
\hline Sex (\% female) & $3092(21.6)$ & $264(36.4)$ & $<0.001$ \\
\hline Urgency & & & $<0.001$ \\
\hline Elective & $6332(44.1)$ & $181(25.0)$ & \\
\hline Urgent & $7364(51.3)$ & $484(66.8)$ & \\
\hline Emergent & $635 \quad(4.4)$ & $59 \quad(8.1)$ & \\
\hline Ejection fraction, $\%$ & & & 0.80 \\
\hline$<30$ & $650 \quad(4.5)$ & $31 \quad(4.3)$ & \\
\hline $30-50$ & $3776(26.3)$ & $201(27.7)$ & \\
\hline$>50$ & $9151(63.8)$ & $458(63.2)$ & \\
\hline Missing & $768 \quad(5.4)$ & $35 \quad(4.8)$ & \\
\hline \multicolumn{4}{|l|}{ Comorbid conditions } \\
\hline Diabetes mellitus & $4212(29.4)$ & $179(24.7)$ & 0.007 \\
\hline COPD & $1653(11.5)$ & $88(12.1)$ & 0.62 \\
\hline Hypertension & $8624(60.1)$ & $446(61.5)$ & 0.47 \\
\hline Congestive heart failure & $1709(11.9)$ & $166(22.9)$ & $<0.001$ \\
\hline Preoperative renal insufficiency & $486 \quad(3.4)$ & 71 (9.8) & $<0.001$ \\
\hline Cerebrovascular disease & $1382(9.6)$ & $127(17.5)$ & $<0.001$ \\
\hline Peripheral vascular disease & $1928(13.4)$ & $141(19.4)$ & $<0.001$ \\
\hline Previous Ml & $8349(58.2)$ & $456(62.9)$ & 0.01 \\
\hline \multicolumn{4}{|l|}{ Other factors } \\
\hline Reoperative surgery & $691 \quad(4.8)$ & $50 \quad(6.9)$ & 0.01 \\
\hline Critical left main stenosis & $3236(22.6)$ & $227(31.3)$ & $<0.001$ \\
\hline
\end{tabular}

Note: $\mathrm{COPD}=$ chronic obstructive pulmonary disease, $\mathrm{MI}=$ myocardial infarction. narians (9.2 v. $3.8 \% ; p<0.001)$. In multivariate analysis, age of at least 80 years was significantly and independently associated with increased odds of death (odds ratio [OR] 2.64, 95\% confidence interval [CI] 1.95-3.57) (Appendix 1). The overall adjusted mortality (for all years combined) was significantly higher for the octogenarians $(6.65 \% \mathrm{v}$. $3.92 \% ; p<0.001)$. Over time, the crude mortality decreased in both age groups. After adjustment for differences in patient populations over time, mortality declined significantly over the period of the study (for patients less than 80 years of age, $p$ trend $<0.001$; for patients 80 years of age and older, $p$ trend $<0.001$ ) (Fig. 1). The gap in adjusted mortality between the older and the younger patients appeared to narrow over time (Fig. 1).

Postoperative stroke occurred in $4.7 \%$ of the older patients and $1.6 \%$ of the younger patients $(p<0.001)$. Overall, the older patients had a significantly greater risk of stroke (multivariate analysis: OR 3.25, 95\% CI 2.15-4.93) (Appendix 1). In contrast to the rate of death, the crude incidence of stroke did not change significantly over the period of the study, ranging from $2.4 \%$ to $7.8 \%$ among the older patients and from $1.2 \%$ to $1.8 \%$ among the younger patients. Multivariate analysis indicated no significant change in the incidence of stroke over time for either older or younger patients $(p=0.61$ and 0.08 respectively for trend over time) (Fig. 2). For all years combined, the adjusted stroke rates were $1.7 \%$ for the younger patients and $3.3 \%(p<0.001)$ for the older patients. However, there was marked variation from year to year in the adjusted stroke

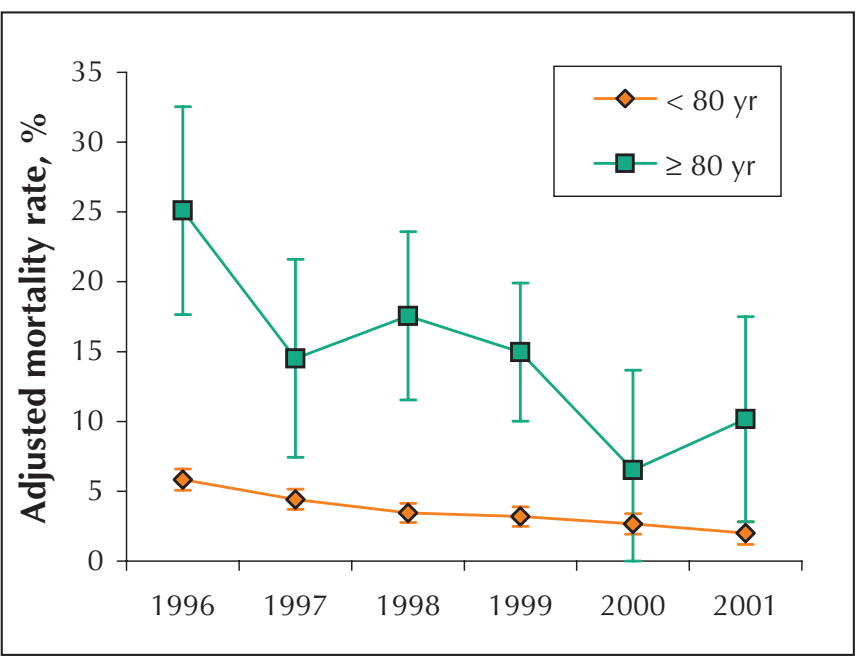

Fig. 1: Adjusted mortality over time (with $95 \%$ confidence intervals). For patients less than 80 years old, $p$ for linear trend $<$ 0.001 ; for those 80 years of age and older, $p$ for linear trend $<$ 0.001 . The rates were adjusted for the following variables: centre, sex, urgency, presence of diabetes, preoperative renal failure, ejection fraction, hypertension, cerebrovascular disease, peripheral vascular disease, chronic obstructive pulmonary disease, heart failure, previous myocardial infarcation, redo surgery, left main disease; age and year of surgery were excluded. 
rate for the older patients (Fig. 2).

Our data demonstrated that surgery was urgent or emergent for a large proportion of the octogenarians and that the rate of death in this group was higher than we had expected or predicted from the data. A comparison of crude outcomes stratified by age and urgency of surgery showed a marked interaction between these 2 variables (Table 2). The octogenarians had only a slightly greater risk for adverse events when undergoing elective surgery than the younger patients $(3.9 \%$ v. $2.9 \%$ for death, $1.9 \%$ v. $1.2 \%$ for stroke). In contrast, the octogenarians requiring urgent CABG had a substantially greater rate of death than those undergoing elective surgery $(10.3 \%$ v. $3.9 \%)$, as well as a markedly greater stroke rate $(5.4 \%$ v. $1.9 \%)$ (Table 2$)$. In a multivariate analysis using an interaction term for age group and urgency, octogenarians undergoing elective CABG had only a slightly, and nonsignificantly, greater risk of death (OR 1.31, 95\% CI 0.60-2.90) or stroke (OR $1.59,95 \%$ CI $0.57-4.44)$ than non-octogenarians undergoing elective surgery (Table 3 ).

\section{Interpretation}

The proportion of patients undergoing CABG who were 80 years of age or older increased steadily over the period of this study. We also found that octogenarians who were undergoing isolated $\mathrm{CABG}$ had more comorbidities and greater clinical acuity than non-octogenarians. Rates of

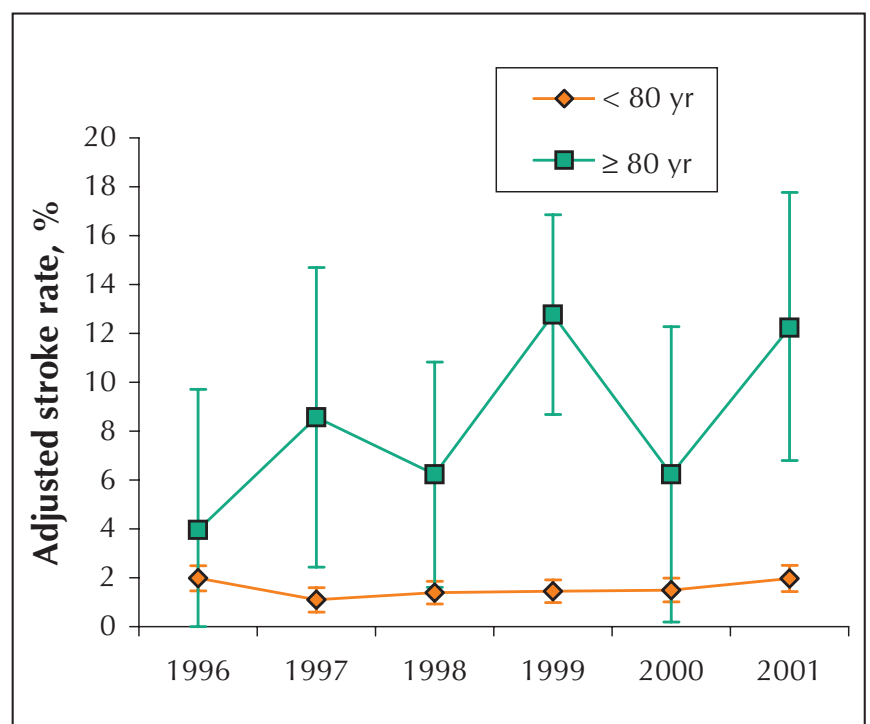

Fig. 2: Adjusted stroke rates over time (with $95 \%$ confidence intervals). For patients less than 80 years old, $p$ for linear trend $=0.61$; for those 80 years of age and older, $p$ for linear trend $=$ 0.08 . The rates were adjusted for the following variables: centre, sex, urgency, presence of diabetes, preoperative renal failure, ejection fraction, hypertension, cerebrovascular disease, peripheral vascular disease, chronic obstructive pulmonary disease, heart failure, previous myocardial infarction, redo surgery and left main disease; age and year of surgery were excluded. death were higher among the octogenarians, but decreased over time in both age groups, and there was evidence that the gap in outcomes between groups was decreasing. Riskadjusted rates of postoperative stroke, meanwhile, remained generally steady over time, at higher levels among octogenarians than among non-octogenarians.

Notably, however, the greater risk of death and stroke for octogenarians was most pronounced among patients undergoing urgent procedures, whereas the differences were smaller for patients undergoing elective surgery.

Collectively, these findings highlight that CABG surgery for elderly patients is increasing in Canada and that operative mortality is decreasing. Our analysis stratified by surgical urgency demonstrates that $\mathrm{CABG}$ can be performed electively in octogenarians with outcomes approaching those of younger patients, which suggests that advanced patient age should not, in isolation, deter a decision to perform CABG when other clinical factors dictate a need for the procedure.

Table 2: Rates of death and stroke among patients, by age, related to the urgency of surgery

\begin{tabular}{|c|c|c|c|c|}
\hline \multirow[b]{2}{*}{ Age group, yr } & \multicolumn{4}{|c|}{ Urgency; \% of patients } \\
\hline & \multicolumn{2}{|c|}{ Elective } & Urgent & Emergency \\
\hline \multicolumn{5}{|l|}{ Death } \\
\hline$<70$ & \multicolumn{2}{|c|}{2.2} & 2.9 & 9.8 \\
\hline $70-74$ & \multicolumn{2}{|c|}{3.8} & 4.9 & 16.5 \\
\hline $75-79$ & \multicolumn{2}{|c|}{6.6} & 6.8 & 16.9 \\
\hline All $<80$ & \multicolumn{2}{|c|}{2.9} & 3.9 & 12.1 \\
\hline$\geq 80$ & \multicolumn{2}{|c|}{3.9} & 10.3 & 17.0 \\
\hline \multicolumn{5}{|l|}{ Stroke } \\
\hline$<70$ & \multicolumn{2}{|c|}{1.0} & 1.1 & 2.6 \\
\hline $70-74$ & \multicolumn{2}{|c|}{1.7} & 2.9 & 1.6 \\
\hline $75-79$ & \multicolumn{2}{|c|}{2.1} & 4.4 & 4.5 \\
\hline All $<80$ & \multicolumn{2}{|c|}{1.2} & 1.9 & 2.7 \\
\hline$\geq 80$ & \multicolumn{2}{|c|}{1.9} & 5.4 & 6.8 \\
\hline \multicolumn{5}{|c|}{$\begin{array}{l}\text { Table 3: Adjusted* risks of death and stroke among patients, } \\
\text { by age, according to the urgency of surgery }\end{array}$} \\
\hline \multirow{2}{*}{$\begin{array}{l}\text { Age } \\
\text { group, yr }\end{array}$} & \multicolumn{4}{|c|}{ Urgency; OR $(95 \% \mathrm{Cl})$} \\
\hline & Elective & & gent & Emergency \\
\hline \multicolumn{5}{|l|}{ Death† } \\
\hline$<80$ & Reference & 1.0 & 84-1.24) & $2.83(2.90-3.85)$ \\
\hline$\geq 80$ & $1.31(0.60-2.90)$ & 2.4 & $74-3.52)$ & $3.19(1.45-6.99)$ \\
\hline \multicolumn{5}{|l|}{ Stroke $\neq$} \\
\hline$<80$ & Reference & 1.4 & 06-1.89) & $2.06(1.19-3.58)$ \\
\hline$\geq 80$ & $1.59(0.57-4.44)$ & 3.3 & 04-5.36) & $4.09(1.36-12.29)$ \\
\hline
\end{tabular}

Notes: $\mathrm{OR}=$ odds ratio, $\mathrm{Cl}=$ confidence interval

*The following variables were included: sex, year of surgery, centre, ejection fraction, diabetes mellitus, COPD, hypertension, preoperative renal insufficiency, congestive heart failure, cerebrovascular disease, peripheral vascular disease, previous MI, reoperative surgery, critical left main stenosis, age-urgency interaction term.

$+C$ statistic $=0.77$.

$\ddagger C$ statistic $=0.72$. 
In a recent study from Hamilton, Ont., results for octogenarians were not worse than those for patients 70 to 79 years of age. ${ }^{3}$ However, in contrast to the present study, the number of octogenarians was small $(n=71)$, and the patients' risks were generally lower than for the younger comparison cohort. In addition, the octogenarians accounted for only $3 \%$ of all patients from the centre, which indicates that this group of octogenarians was probably highly selected and of low surgical acuity.

The current study had a number of important limitations. Even with more than 15000 patients and more than 700 patients who were octogenarians, the statistical power to assert that there was no significant difference in outcomes among elective patients was limited. However, the differences were relatively small for these patients and, overall, appeared to be diminishing over time.

In addition, this study included only patients who actually underwent CABG and did not compare outcomes in those with disease who underwent medical therapy alone or percutaneous coronary interventions. It has become clear from other research that elderly patients derive a substantial benefit from revascularization in terms of quality of life, reduction in major cardiac events and mortality. ${ }^{10,12}$

A more detailed examination of octogenarians undergoing urgent (i.e., nonelective) CABG, as well as the clinical management of these patients before surgery, is warranted to determine whether suboptimal timing of surgery contributes to the poor outcomes seen after urgent procedures.

This article has been peer reviewed.

From the Department of Surgery, Dalhousie University, Halifax, NS (Baskett, Buth, Hirsch); the Department of Surgery, University of Calgary, Calgary, Alta. (Ghali, Maitland); the Department of Surgery, University of Alberta, Edmonton, Alta. (Norris, Ross); The New Brunswick Heart Centre, Saint John, NB (Maas, Forgie)

Competing interests: None declared.

Contributors: Roger Baskett was involved in the study design, data analysis and writing of the manuscript. Karen Buth designed and carried out most of the analysis and contributed to drafting the manuscript. William Ghali helped to design the study and analysis and contributed to drafting the manuscript. Colleen Norris and Andrew Maitland participated in data acquisition and interpretation. Tony Mass participated in the study design and data acquisition. David Ross was involved in the study design and data analysis; he also helped to draft the manuscript. Rand Forgie was involved in the study design and data interpretation. Gregory Hirsch was involved in the study design and data interpretation; he also helped in drafting the manuscript. All the authors were involved in revising the draft manuscript and gave final approval of the manuscript.

\section{References}

1. Peterson E, Cowper P, Jollis JG, Bebchuk JD, DeLong ER, Muhlbaier LH, et al. Outcomes of coronary artery bypass graft surgery in 24461 patients aged 80 years or older. Circulation 1995;92(9 suppl):II85-91.

2. Alexander K, Anstrom K, Muhlbaier L, Grosswald RD, Smith PK, Jones RH, et al. Outcomes of cardiac surgyer in patients age $\geq 80$ years: results from the National Cardiovascular Network. 7 Am Coll Cardiol 2000;35(3):731-8.
3. Smith K, Kent R, Lamy A, Arthur H, Gafni A. Outcomes and costs of coronary artery bypass grafting: comparison between octogenarians and septuagenarians at a tertiary care centre. CMA7 2001;165(6):759-64.

4. Fruitman D, MacDougall C, Ross D. Cardiac surgery in octogenarians: can elderly patients benefit? Quality of life after cardiac surgery. Ann Thorac Surg 1999;68:2129-35.

5. MacDonald P, Stadnyk K, Cossett J, Klassen G, Johnstone D, Rockwood K. Outcomes of coronary artery bypass surgery in elderly people. Can 7 Cardiol 1998;14(10):1215-22.

6. Craver JM, Puskas JD, Weintraub WW, Shen Y, Guyton RA, Gott JP, et al 601 octogenarians undergoing cardiac surgery: outcomes and comparison with younger age groups. Ann Thorac Surg 1999;67:1104-10.

7. Freeman $W$, Schaff H, O'Brien P, Orszulak T, Naessens J, Tajik A. Cardiac surgery in the octogenarian: perioperative outcome and clinical follow-up. $\mathcal{F}$ Am Coll Cardiol 1991;18:29-35.

8. Williams D, Carrillo R, Traad E, Wyatt CH, Grahowksi R, Wittels SH, et al. Determinants of operative mortality in octogenarians undergoing coronary bypass. Ann Thorac Surg 1995;60:1038-43.

9. Ghali WA, Graham MM. Evidence or faith? Coronary artery bypass grafting in elderly patients. CMA7 2001;165:775-6.

10. Graham M, Ghali W, Faris P, Galbraith P, Norris C, Knudtson M; Alberta Provincial Project for Outcomes Assessment in Coronary Heart Disease (APPROACH) Investigators. Survival after coronary revascularization in the elderly. Circulation 2002;105:2378-84.

11. Sollano J, Rose E, Williams D, Thornton B, Quint E, Apfelbaum M, et al. Cost-effectiveness of coronary artery bypass surgery in octogenarians. Ann Surg 1998;228:298-306.

12. TIME Investigators. Trial of invasive versus medical therapy in elderly patients with chronic symptomatic coronary artery disease (TIME): a randomized trial. Lancet 2001;358(9286):951-7.

13. Shroyer AL, Plomondon ME, Grover FL, Edwards FH. The 1996 coronary artery bypass risk model: The Society of Thoracic Surgeons Adult Cardiac National Database. Ann Thorac Surg 1999;67:1205-8.

14. Hosmer D, Lemeshow S. Applied logistic regression. New York: John Wiley and Sons; 1989.

Correspondence to: Dr. Roger Baskett, Queen Elizabeth II Health Science Centre, 1796 Summer St., Rm 2269, Halifax, NS

B3H 3A7; fax 902 473-4448; rbaskett@dal.ca

Appendix 1: Variables in model for mortality and stroke

Mortality model $(C$ statistic $=\mathbf{0 . 7 8})$

Age ( $<70$ years, $70-74$ years, $75-79$ years, $\geq 80$ years), sex, year of surgery, centre, urgency (elective, urgent, emergent), ejection fraction $(<30 \%, 30 \%-50 \%,>50 \%)$, diabetes mellitus, chronic obstructive pulmonary disease, hypertension, preoperative renal insufficiency, congestive heart failure, cerebrovascular disease, peripheral vascular disease, previous myocardial infarction, reoperative surgery, critical left main stenosis

Stroke model $(C$ statistic $=\mathbf{0 . 7 5})$

Age ( $<70$ years, $70-74$ years, $75-79$ years, $\geq 80$ years), sex, year of surgery, centre, urgency (elective, urgent, emergent), ejection fraction $(<30 \%, 30 \%-50 \%,>50 \%)$, diabetes mellitus, chronic obstructive pulmonary disease, hypertension, preoperative renal insufficiency, congestive heart failure, cerebrovascular disease, peripheral vascular disease, previous myocardial infarction, reoperative surgery, critical left main stenosis 